stages a hyaline circular sheath can be distinguished around the sclerotic granule but eventually the sheath ruptures and it appears as if the sclerotic mass is surrounded by a sheath of black radiating hyphæ. Some of these sclerotic granules coalesce in pairs, and sometimos in threes, producing a big granule up to $75 \mu$ in diameter. The small isolated granules range in diameter from 12 to $45 \mu$.

Sclerotic granules were also produced on trypticase soy agar plates streaked with $S$. griseus strain A.T.C.C. No. 10137 and incubated for $72 \mathrm{hr}$. at $25^{\circ} \mathrm{C}$. The granules in this case were morphologically different from those of the strain isolated from Lethbridge soil as they were more or less circular. No sclerotic granules were produced by $S$. antibioticus A.T.C.C. 8663, S. lavendulae A.T.C.C. No. 8664, S. scabies St. Catharines No. VI-3a-3 obtained from the Bacteriology Division, Science Service, Canada Department of Agriculture, Ottawa, Ontario, and $S$. venezuelae obtained from the Prairie Regional Laboratory, Saskatoon, Saskatchewan. Aerial mycelium with spores but without sclerotic granules was produced when the S. griseus strain isolated from Lethbridge soil was grown on glucose peptone medium, potato dextrose agar, 'Bacto Tryptone' glucose agar and 'Bacto Sabouraud' maltose agar. On 'Bacto Endo' agar and 'Bacto' nutritive caseinate agar neither aerial mycelium with spores nor sclerotic granules were produced.

When the sclerotic granule-producing strains of S. griseus A.T.C.C. No. 10137 and the one isolated from Lethbridge soil were streaked on media containing trypticase and phyton (components of trypticase soy agar) separately no granules were produced. This indicates that, at least with these two strains, both the constituents should be present in the same medium for the production of sclerotic granules.

In the light of these investigations it will be seen that the production of sclerotic granules can occur in strains of Streptomyces griseus and that there is no justification for creating the new genus Chainia on the basis of the production of these structures.

I am grateful to Dr. M. W. Cormack, officer-incharge, Plant Pathology Section, Science Service Laboratory, Canada Department of Agriculture, Lethbridge, Alberta, and Dr. W. C. Broadfoot, chief, Science Service Laboratory, Canada Department of Agriculture, Lethbridge, Alberta, for kind suggestions.

Plant Pathology Section,

$$
\text { M. L. Gattani* }
$$

Science Service Laboratory,

Canada Department of Agriculture,

Lethbridge, Alberta, Canada.

* Post-doctorate Fellow of the Canada Department of Agriculture in co-operation with the National Research Council of Canada. 1 Thirumalachar, M. J., Nature, 176, 934 (1955).

\section{Sarcocystis sp. in the Red-legged Partridge, Alectoris rufa, and the Pheasant, Phasianus colchicus}

A RED-LEGGED partridge, Alectoris rufa, was sent to this laboratory from Norfolk for post-mortem examination. It was an old cock which had died of a heavy infestation of Syngamus trachea, but it was also parasitized with a species of Sarcocystis.

The main sites of infection were the superficial pectoral muscles, which were obviously streaky, dehydrated and aerated. The structure of the individual muscle fibres had broken down, and many cysts could be seen under low magnification. They were oval and measured $100-165 \mu \times 60-110 \mu$, with a laminated wall, and contained large numbers of crescent-shaped spores, some of which were degenerating.

Erickson ${ }^{1}$ records species of Sarcocystis (Sporozoa; Sarcosporidia) from eight orders of birds. The only gallinaceous host is the domestic fowl, from which v. Ratz (1908) recorded S. horvathi in Hungary, and Krause and Goronoff (1933) recorded $S$. gallinarum in Bulgaria. Other records from fowls are Kuhn, 1865, and Haines (quoted in Stiles), 1894. Only the first article is available to me here.

A similar infection with cysts of the same size and appearanee was seen five years ago in a wild pheasant, also from Norfolk. Once again, the superficial pectoral muscles were affected.

Occasional cases of mallard, infected with S. rileyi have been seen, but this would seem to be the first time $A$. rufa and $P$. colchicus have been recorded as hosts.

Game Research Station,

P. A. Clapham

Burgate Manor,

Fordingbridge,

Hampshire.

${ }^{1}$ Erickson, A. B., Auk, 57 (4), 514 (1940).

\section{Effect of Benzimidazole on Detached Wheat Leaves}

Detached wheat leaves when floated on water retain their green colour for a few days only and are usually chlorotic within a weok. During a study of the effects of analogues of nucleic acid components on detached wheat leaves we noticed that those that floated on $30-100$ p.p.m. of benzimidazole retained their green colour and their capacity to support growth of leaf and stem rusts of wheat for periods up to at least one month. Other compounds reported to be analogues of essential purines and pyrimidines (barbituric acid, 2-amino-4-methyl pyrimidine, 2,6-diamino purine sulphate, thiouracil, 2-chloro-4-mothyl benzoic acid at 1-1,000 p.p.m. or azaguanine and azaadenine at $50-100$ p.p.m.) did not give this effect. Similarly, there was no effect with the purines, adenine and guanine, and the pyrimidines, thymine, cytosine and uracil at 50-200 p.p.m.

The action of benzimidazole in preventing the destruction of chlorophyll was further investigated. Leaves of Triticum compactum (var. Little Club) were detached and floated on 50 p.p.m. benzimidazole and on water. The detached leaves were kept in 6-hr. light periods of 800 foot-candles alternated with 18-hr. dark periods. The temperaturo was maintained at $20^{\circ} \mathrm{C}$. in the light and $13^{\circ} \mathrm{C}$. in the dark. Under these conditions microbial development was minimal. Respiration-rates, water-soluble nitrogen and alcohol-insoluble nitrogen wero determined at intervals up to 13 days after detachment.

When the colour-value of normal leaves was rated at five and that of leaves devoid of green at zero, the colour of leavos on the benzimidazole solution remained at five for the thirteen days. The colour of the leaves floated on water was estimated at four on the fourth, two to three on the eighth, and one to two on the thirteenth day. The respiration-rate was lower on treated leaves than on those floated on water 